\title{
Initiation, Hazing or Orientation? \\ A case study at a South African University
}

\author{
Vivian de Klerk (Corresponding author) \\ Rhodes University \\ P.O. Box 94 Grahamstown, South Africa \\ E-mail: v.deklerk@ru.ac.za
}

Received: May 8, 2013 Accepted: June 18, 2013 Published: July 17, 2013

doi:10.5296/ire.v1i1.4026 URL: http://dx.doi.org/10.5296/ire.v1i1.4026

\begin{abstract}
In this paper I explore the various meanings of the term 'initiation', in the context of certain traditions and practices at Universities, which can cause personal physical or psychological harm if not contained and regulated. The paper focuses on a case study of the practice of 'serenading' at a small residential University. It draws on an eclectic assortment of methodological approaches in order to get closer to the 'truth' about this social practice, and to assess whether it should be viewed as a form of initiation, or as something which is intrinsically positive. These methodological approaches include a deeply personal account, rooted in narrative research, and the results of two large-scale surveys. Results accord with social identity theory (Tajfel \& Turner, 1979), in terms of which group identity tends to override personal identity in certain contexts where belonging and fitting in is important, and with cognitive dissonance theory (Aronson \& Mills, 1959; Keating et al., 2005), in terms of which people tend to attribute a greater value to something they had to put a lot of effort into doing or achieving (as opposed to its actual worth). These demanding and humiliating tasks lead new initiates to increase the subjective value of the group, and this contributes to group loyalty and solidarity. Those students who had 'survived' the tradition were keen to impose it on new students, and argued that it is good for them. But selected personal accounts and the survey results suggest that the practice was not entirely free of coercion, and that there is some danger in allowing certain traditions to reproduce 'dominant discourses' which inevitably construct certain students (the ones who do not wish to participate) in deficit terms.
\end{abstract}

Keywords: initiation, hazing, university, peer pressure 


\section{Introduction}

"Initiation" is derived from the Latin word initium - an "entrance" or "beginning". Typically it involves a rite of passage or ceremony marking acceptance into a group (gang, team, age cohort)of some kind. Metaphorically it can involve "a transformation, in which the initiate is 'reborn' and starts afresh in a new role. This definition applies to many harmless and socially accepted induction ceremonies such as baptism, confirmation or university graduation, each of which has clearly defined objectives, and serves a useful purpose of introducing, acclimatising and 'starting' an individual in a new and foreign (possibly uncomfortable) environment.

However, increasingly in the modern world, and in tertiary institutions, the word 'initiation' has come to refer to activities that are potentially humiliating or degrading, often involving some coersion, and the risk of emotional or physical harm. In America, the term "hazing" is the common equivalent. While mild initiation may involve nothing more than the pranks or antics of young students, there are forms of initiation imposed by the group on a newcomer that lead to harassment, abuse and humiliation. When peer pressure is exerted by a group on other individuals in order that they 'voluntarily' conform to norms, under the threat of ostracization or other negative consequences, one moves into a very different and negative interpretation of the word 'initiation', and it is this concept that is explored further in this paper.

Hoover and Pollard's (1999) National Survey in the United States of some 60,000 student athletes from 2,400 institutions revealed that a quarter of them experienced some form of hazing in order to join a team. Of these, one in five were forced to do something or humiliated in some way, half of these acts involved alcohol and 2/3 involved embarrassing apparel, sleep deprivation, or unhygienic behaviour.

In the most comprehensive survey to date of 53 institutions in the United States involving over 11,000 undergraduates, Allen and Madden defined hazing as "any activity expected of someone joining or participating in a group that humiliates, degrades, abuses, or endangers them regardless of a person's willingness to participate" (2008:2) These behaviours are embarrassing, dangerous, and potentially illegal, and typically include alcohol consumption; public humiliation; isolation; sleep-deprivation (including being woken very late or early); public performances or skits of a potentially embarrassing nature; being made to sing or chant with a group in a public situation; wearing clothing that is potentially embarrassing; acting as a servant to others; associating only with specific people, being tied up or confined, being dropped off at an unfamiliar location, drinking large amounts (of water or alcohol), and performing or miming of sexual acts (op. cit. 2008:9).

The most worrying aspect about such phenomena is the positive views that most participants hold about them. Allan and Maddon's study (2008) reported that 55\% of college students experienced these practices, many had had similar experiences before arriving, and these were not secret: $25 \%$ of staff surveyed knew about these practices, most of which took place on campuses and were subsequently shared in social media etc. Typically students in the survey perceived 'hazing' as something positive rather than negative, and $95 \%$ of them did 
not regard it as worthy of reporting or complaining about, seeing it as an inevitable part of the campus culture. There was minimal criticism offered, and limited awareness that there might be anything 'wrong' or that what they had experienced might be defined as verging on initiation.

It is a cause for concern that very high numbers of participants minimised their experiences ("no big deal", "no one was harmed"), indicated that it was their choice ("I was willing / happy to go along with it"), and rationalised it as inevitable ("I knew it would occur"), enjoyable on reflection ("a positive experience", "feelings afterwards outweighed the ... stress" (op. cit. 29)). Many normalised it, calling it 'tradition', "something everyone went through", or denied seeing it as initiation at all ("I didn't see it that way until later"). They tended to recognise and expect such activities as part of the campus culture, and to be surprised to hear that there might be anything sinister or negative involved. In fact they resisted using labels such as 'hazing' or 'initiation' for these activities. Seemingly unaware of the social pressure and invisible coercion they might have been subjected to, they preferred to think they had had a choice, they had not felt really uncomfortable or threatened, and nothing had happened against their will. As one student put it: "I think hazing is something you are kind of forced to do to be part of something against your will. I think of it as fun and something one wants to do, then it shouldn't be considered hazing" (2008:34).

Such initiation can and does cause personal physical or psychological harm if not contained and regulated. Other such risks for the institution include students leaving, abusive campus climates and negative publicity. The tendency to be lenient and dismiss such activities as harmless fun, or to condone them, has the potentially dangerous result of entrenching attitudes and beliefs that such practices are 'normal'. Overlooked, ignored and neglected and largely understudied (with notable exceptions such as Allen \& Madden, 2008; Hoover \& Pollard, 1999; Jones, 2004; Nuwer, 1999, 2000), the phenomenon will continue to plague institutions unless proactive intervention takes place.

This paper aims to throw some light on a particular practice or 'tradition' at a South African University known as 'serenading', to explore the attitudes of various role-players to the practice, and try to determine whether or not it should be viewed as a form of initiation.

\section{Method}

Niglas (2004) makes the important point that in any research, the problem (rather than one's philosophical position) should determine the overall strategy, which might be qualitative, quantitative or both, since they are not mutually exclusive. Indeed, they can complement each other, so the primary concern should be fitness for purpose (Hammersley, 1995), existing knowledge, and the local context (including practicalities such as access, data collection, avoiding bias etc.). Following these principles, this paper uses an eclectic assortment of methodological approaches in order to get closer to the 'truth' about the social practice of 'serenading', in trying to assess whether it should be viewed as a form of initiation, or as something which is intrinsically positive. In part, the paper draws on a deeply personal account, rooted in narrative research, which is well-established in the social sciences as a way to represent authentic subjective accounts, which are often detailed and complex 
(Bonilla-Silva, 2000; Bonilla-Silva, Lewis, \& Embrick, 2004; Plummer, 1995). In order to complement this narrative, the rest of the paper is based on two surveys. Each of these approaches is discussed briefly below.

When used to the full extent, narrative research is based on a small number of detailed accounts of participants, who are asked to tell their stories in a variety of forms(Vincent, 2008:4). Using stories of this kind, we gain insight into social processes, structures, relationships and situations (Aguirre, 2000, p. 3), and this particular study draws on the spontaneous account (or 'story') of a student's experience of serenading. It thus meets Bonilla-Silva, Lewis and Embrick's requirement of emerging "at [a] certain historical moment(s) for a specific reason" (2004, p. 556). In writing her story and recounting her experiences during an intensely emotional time, the writer drew on her available discourses to reflect on who she was and how she felt at this particular moment of change, as a new student at a new institution.

Despite Steedman's (1986) claim that the stories that people tell are often "in deep and ambiguous conflict with the official interpretive devices of a culture" (Vincent, 2008:1), because this account was written very close to the time of the experience, it is less likely to fall victim to the problem that 'individuals twist and turn, reinterpret and falsify, repress and forget their experiences in pursuit of a construction of their personality to which the past has to be subordinated' (Haug, 1992, p. 20). It can probably reliably be regarded as a close representation of her reality - how it really was for her - and it should assist in placing her into the existing social structures (Vincent, pp. 4-5).

This personal narrative is balanced with feedback from an extensive consultative process within the residences, and data from two large surveys, which were conducted shortly after the event in question. While surveys can answer questions, solve problems, assess needs, determine whether or not aims have been met, establish baselines against which future comparisons can be made, analyze trends across time, and "generally describe what exists, in what amount, and in what context" (Isaac \& Michael, 1997, p. 136), such research can only offer a fair degree of precision, and it is always somewhat subjective (Salant \& Dillman, 1994). The main value of a survey lies in the insights provided from interrogation of the data (Salant \& Dillman, 1994, p. 2), and in being able to generalize and elicit information about attitudes that would otherwise be difficult to measure (McIntyre, 1999, p. 75).

Eduardo Bonilla-Silva points out several weaknesses in surveys, and stresses how difficult it can be to interpret the 'somewhat mysterious meaning of check marks on restricted questions and items' (2003, p. 64), as representations of a data set of individual 'attitudes', and connecting them to a larger system, such as race or social privilege. In his view, by summarising the answers to questionnaires and surveys, one fixes subjectivity rather than permitting multiple, changing and often contradictory self-understandings. He also points out that considerations of social acceptability often influence responses, and true feelings and prejudices are disguised. His preference is for a more personal approach, using discussions and one-on-one interviews. The sample was small, however, and it is arguable that informants would be less likely to mask their prejudices in an anonymous survey than during 
an interview (see further critique in de Klerk \& Radloff, 2009). When surveying views on a topic such as 'serenading', which is not highly sensitive, guarantees of anonymity are likely to mitigate any tendency to respond in a politically correct way (cf. Salant \& Dillman, 1994, p. 20). Nevertheless, the idea that informants might intentionally lie because of peer pressure to maintain the social practice does need to be kept mind (Aronson \& Mills, 1959; Kamau, 2012).

Obviously success or failure also depends on the nature of the questions (whether they actually elicit useful answers that provide reliable and valid measures of something we want to describe), the language used, and the overall length of the survey as a whole (McIntyre, 1999, p. 77; Salant \& Dillman, 1994, p. 93). The overall aim in this research was to triangulate different kinds of data from three sources: a personal account, feedback from discussion groups and data from surveys, in order to answer the questions posed.

\section{The Context}

The University under study is the smallest in South Africa, with approximately 7500 students studying in 6 different Faculties. Approximately $1 / 4$ of the student body is international, and $1 / 4$ are postgraduate. Over $50 \%$ of all students at the university live in one of 52 residences, including almost all of the first year students. Residences vary in size, with an average number of around 70 students per residence.

Each year, one week before the official term starts, orientation (informally known as O-week) begins, when efforts are made to help the first year students adjust and acclimatize and find their bearings. This is a form of induction into University life, which aims to foster a culture which promotes tolerance and respect for human rights and celebrates diversity, to create an appropriate environment for living and learning in harmony, to enhance equity in respect of race, gender and sexual orientation, placing high value on the uniqueness, personal dignity and self-worth of every student. While keeping the focus on academic induction with a range of introductory lectures to all subjects running through the week, additional workshops and social activities are included, to encourage students to balance academic and social activities, and to make lasting friendships, emphasizing the essential balance between personal freedom and social obligations in residential communities. These social aspects are handled by the Wardens and student leaders in the residences, who are trained beforehand to run workshops, and guide discussions around important social issues such as diversity, substance abuse etc.

While alumni of the university recount stories of initiation practices in the early years, which included several of the activities listed in this paper, the University officially banned any forms of initiating first year students in the 1970s, after which those that have persisted (such as drinking and sports clubs) have gone 'underground'. However, a new practice has slowly evolved to take the place of obvious initiation. Unobtrusively and unnoticed, over the past 20 years an apparently harmless practice developed, which became known as 'serenading'. Each residence would devise and practice a song, and make 'appointments' with residences of the opposite gender in order to perform these musical renditions at the start of each day, after which they would enjoy a cup of coffee and a chat before making their way back to start the formal programme of lectures. The aim was to enable students to meet each other and have 
some fun.

Unfortunately, like all such 'traditions', serenading became increasingly 'baroque' over the years. Starting times became earlier and earlier, song lyrics became increasingly suggestive, and sexy dance moves crept in, along with questionable dress requirements (such as pyjamas), dodgy procedures to match up conversational pairs (such as selecting room keys), and potentially embarrassing formulaic structures for obligatory public dialogues. All this operated under the radar as it were, and authorities, including the wardens, turned a blind eye to what was seen as a harmless bit of student fun. In 2012, the Office of the Dean of Students went ahead with its annual training of the residence leadership teams, and the Vice Chancellor made his usual public pronouncement to first years and their parents that at Rhodes University there is no tolerance of racist, sexist, homophobic, xenophobic or any other kind of chauvinist behavior, and that everyone deserves respect and dignity.

\section{Methodology}

The overall aim in this research was to triangulate different kinds of data from three sources: a personal account, feedback from discussion groups and data from surveys, in order to answer the questions posed.

\subsection{A Narrative Account: One Student Speaks up}

Three days into O-week, a student sent an eloquent letter to the Dean of Students and the Vice Chancellor, in which she indicated that she was considering withdrawing from the University because of the trauma caused to her by serenading. Her detailed account told of shrill and insistent 5:30 wake-up calls each morning followed by a panic-stricken scramble to be on time for a pre-'inspection' by sub wardens; long compulsory evening practices demanding increasing levels of frenzy and excitement from performers; being sent out in pyjamas to watch boys dressed in T-shirts and boxers sing to them, accompanied by "pelvis rolling and crass lyrics"; being instructed to serenade a men's res in return ("we roll our butts like strippers, the boys cheer. We push our breasts out, shake our hips, and gyrate our pelvis. All in accordance with the routine we have been taught. And the boys yell, 'Yeah!' as their eyes pop"). She described an 'icebreaker' session involving women's room keys being anonymously handed to the boys, who call out numbers and assign pairs to have friendly chats. Topics handed out caused embarrassment ("propose to each other"; "find out the guy's favourite movie, and say 'in my pants' at the end of presenting his details. Someone's favourite was "Grease”... in my pants. Ha").

In her letter, the student depicted the "war of principles" inside her: part of her aware that serenading is a silly dance, aimed to break the ice, and being enjoyed by most of her peers; the other part fiercely opposed to the idea that, with a student population that is $59 \%$ female, she should find herself part of a process so hugely demeaning and undermining of women ("do we have to make it as easy as letting a boy call out a girl's number and have her present herself?"). Deeply critical of what such a practice represented, symbolically, and yet equally aware that it was not unbearable, everyone else was coping, and that she should too ("sure, I thought I could suck it up"). Her inner conflict raged, one part of her determined not to 
participate in "that kind of humour", the other feeling pressured to play along, and avoid being booed. ("So what do I do? I just got here, do I refuse to say it, and get booed by my new peers? Do I say it, and feel sick inside? Because yes, that is my response, whether it's intense or not, that's how I feel").

Her point was made forcefully: by turning a blind eye to sexist behavior which is heterosexually normative, the institution could be accused of condonement, if not encouragement, of such behavior. The implicit message conveyed to young women by this practice is that it is appropriate to feel validated when a man leers or shouts approval when eyelids are batted or breasts are shaken, and that these are appropriate gender-based roles. This clashes with more overt messages against sexual discrimination and other chauvinist behavior conveyed publicly by senior University officials, and displayed on posters and T-shirts.

She explained her spiraling panic over those few days, and how she felt worse and worse:"And the tears kept coming. I made it through half a bowl of bran flakes, before the panic in my stomach stoppered my oesophagus. I had to get out of there. I felt like a little girl. They [the warden and subwarden] helped. I still cried, I still panicked but they helped." Eventually she took a few days 'out' and stayed with friends in town until term began. (She received extensive support, changed residence, and settled down successfully during the following week).

In the meantime it became known that some over-enthusiastic student leaders in one of the male residences had physically broken the locks of 16 doors of first-year students in order to 'encourage' them to get up early for their serenading practice. One further complaint a few days later from a politically well-placed parent about serenading caused the University to spring into action, given a context in which the Report of a Ministerial Committee on Institutional Transformation of 2008 had noted that "the experience of feeling discriminated against, in racial and gender terms in particular, is endemic within institutions ... it would not be an exaggeration to suggest that no institution can confidently indicate that the principles of non-racialism and non-sexism ... have been achieved, despite the fact that all institutions have a range of policies in place to address equity and transformation" (Report of the Ministerial Committee 2008, 53). They also noted that patriarchy and sexist behaviour are pernicious and pervasive on several campuses.

A deputation of very senior officials at the University, including the Vice Chancellor and Deputy Vice Chancellor and the Director or Equity and Transformation paid an unexpected visit over the weekend to the two residences from which the two different complaints had arisen. Such a visit was unprecedented, and the Wardens and student leaders were taken aback and overwhelmed by the high-level visit. The message was very clear: the University took such matters extremely seriously. Disciplinary proceedings began immediately in the residence where doors locks had been broken, and the Dean of Students embarked on an extended process of discussions, fact-finding and consultation, in an attempt to find a way forward in order to prevent any further recurrence of what had come to light. 


\subsection{Follow-up Research: Two Surveys}

After releasing (with the student's permission) an edited version of the student's very eloquent letter on a public website to encourage debate, a draft protocol was drawn up, to guide further discussions on the future of serenades at the University. Hall Committees were required to discuss the matter, and then consultations began with elected representatives from each hall, hall wardens, the Students' Representative Council (SRC), and the Dean of Students. The matter was thrashed out between the various parties until all details were agreed upon. Results of these discussions were interesting: residence leadership teams supported the view that generally the practice was a good one, that the complaint, while reflecting one student's version of events, was not representative or typical of how most students experienced serenading, and that it would be a great pity to lose what was viewed by most students and wardens as the 'highlight' of the orientation experience. There was fierce and emotional defence of the tradition, signs of anger against members of senior administration in the University for taking one student's complaint so seriously, and only after considerable pressure was applied was it generally acknowledged that the power relationship between first year students and members of the house committee needed to be re-examined, and a few guidelines needed to be introduced in order to preserve the positive aspects of serenading while preventing any form of coercion and respecting the rights of any student not to participate. The new rules (Appendix A) were hotly contested, and it took several hours of meetings before they made their way to the Board of Residences for approval, and subsequent endorsement by senior management and Senate. Changes included banning the wearing of pyjamas and setting out guidelines for appropriate dress, prohibiting the waking of first years by intercom, alarm, or loud banging, controlling noise levels and emphasising that participation must be strictly voluntary.

During the third term of 2012 the annual Quality of Residence Life survey (completed by all students in residence, ranging from $1^{\text {st }}$ years to post-graduates) included a question about each student's orientation experience that year. Asked to respond on a 5-point scale to the statement "My orientation experience in res was very helpful and positive" (see Table 1), 467 students ( $18 \%$ of the 2582 respondents overall) disagreed or strongly disagreed. This was a disturbing sign that all was not as well as had been assumed.

Table 1. Responses to the statement: "My orientation experience in res was very helpful and positive"

\begin{tabular}{lll}
\hline Frequency & Count & Percentage \\
\hline Strongly disagree & 318 & 12.3 \\
Disagree & 149 & 5.8 \\
Neutral & 719 & 27.8 \\
Agree & 818 & 31.7 \\
Strongly agree & 578 & 22.4 \\
Total & 2582 & 100.0 \\
\hline
\end{tabular}


Feedback in the free comment section of this survey varied from being very positive ("great help ... fun, made adjusting easier" "creates bonds"; "ice-breaking"; "helped me get into the system"; "fun, I met new people"; "serenades were the best part") to neutral or ambivalent ("It was okay I guess"; "I disliked serenades but now I appreciate them"; "Equally good and bad") to distinctly negative ("really did not like serenades"; "Serenades were a torture"; "sexist, objectifying \& unnecessary").In accordance with the protocol, the following year a presentation was made to some 500 student leaders during their training the week before O-week, reminding them of the protocol and providing some of these survey results. The presentation was met with a high level of hostility and outrage from many of these students, who had apparently not been properly briefed by outgoing committees about the discussions the previous year. The tenor of the heated debate conforms closely to Allan and Madden's (2008) findings: Serenading was seen as positive - an inevitable part of campus culture - and since everyone had been through it, there could not be anything 'wrong' with it. Statements were made such as: "we had to do it so they must"; "it is the only way they will get to know each other"; "they will never make friends". Students rejected the negative evidence presented from the survey results, insisting that students didn't really mean what they had said, and must have forgotten or imagined things. A group from one Hall tried to stage a walk-out to signal their outrage.

This accords very well with social identity theory (Tajfel \& Turner, 1979), in terms of which group identity tends to win over personal identity in certain contexts (such as this one) where normative fit is important. One can also draw on cognitive dissonance theory to explain this behaviour: the theory is based on the view that people tend to attribute a greater value to something they had to put a lot of effort into doing or achieving (as opposed to its actual worth). These demanding and humiliating tasks lead the new member to increase the subjective value of the group, and this contributes to his/her loyalty and to the solidarity of the entire group (Aronson \& Mills, 1959; Keating et al., 2005).

In an effort to control the meeting and convince participants that some students really did not enjoy the tradition, the Dean of Students undertook to run a further follow-up survey shortly after orientation in 2013, which every first year student would be encouraged to complete. A firm message was then sent to all residences reminding them of the protocol and orientation began in earnest.

Table 2. Responses to statements on serenading

\begin{tabular}{lll}
\hline & $\mathbf{T}$ & $\mathbf{F}$ \\
\hline I participated in serenading & $94.5 \%(\mathrm{n}=990)$ & $5.5 \%(\mathrm{n}=57)$ \\
My participation was totally voluntary & $96.5 \%(\mathrm{n}=991)$ & $3.5 \%(\mathrm{n}=36)$ \\
$\begin{array}{l}\text { I enjoyed the dancing } \\
\text { I was happy with the lyrics }\end{array}$ & $91.7 \%(\mathrm{n}=937)$ & $8.3 \%(\mathrm{n}=85)$ \\
Serenading helped me meet people & $91.6 \%(\mathrm{n}=938)$ & $8.4 \%(\mathrm{n}=86)$ \\
$\begin{array}{l}\text { My house committee was supportive } \\
\text { encouraging during the practices }\end{array}$ & $90.1 \%(\mathrm{n}=921)$ & $9.9 \%(\mathrm{n}=101)$ \\
\hline
\end{tabular}


One week later, at the first house meeting, first years were given a survey to complete anonymously. The questionnaire explored various aspects of Orientation in general and one subset of statements (Table 2) focused exclusively on serenading, and requested True / False responses. All results were quickly collated, in order to keep the momentum of awareness-raising. The topic of the first Wardens Discussion group was a discussion of these results, which were then widely disseminated.

\section{Discussion: Is Serenading a Type of Initiation?}

It is clear that despite the new protocol, some level of discomfort was still experienced by a fair number of students. The survey shows that 57 students were brave enough to say 'no', and elected not to participate in serenading at all, which is somewhat re assuring, since it indicates that students were given the choice of opting out. However, 36 state that although they did participate, it was not entirely voluntary, which is evidence that peer pressure is still at play. 85 students also indicated a measure of discomfort at the nature of the lyrics and dance moves, despite these having been work-shopped in a consultative way in each residence - again indicative of the hidden power-play at work. Even more interesting is the fact that 101 students were sufficiently discerning to note that their social networks had not expanded, and they had not met people through serenading, although this had been the most persuasive argument provided by the student leaders as one of the stated aims of the tradition. As Vincent (2008), discussing racial integration, notes, increased 'contact' does not amount to greater integration, and the same principle applies to other sorts of integration: putting pressure on students to gather and sing together early each morning will not necessarily achieve anything more than the most superficial of engagements.

Following Bonilla-Silva, Lewis and Embrick (2004, p. 559) state that "actors at the top of a racial order tend to display views, attitudes, and stories that help maintain that privilege, whereas actors at the bottom are more likely to exhibit oppositional views, attitudes and counter narratives". The practice of serenading tends to reflect a similar positioning of actors in the residential hierarchy: just as, those students who have 'survived' the tradition are now in the privileged position of imposing it on newcomers, and they argue that it is good for them. Relations of power and discipline are 'inscribed into the apparently innocent spatiality of social life' (Soja, 1989, p. 6).

One needs to interrogate claims that this practice oils the social wheels of engagement, and ask how much worthwhile contact is really going on. Serenading together is often little more than superficial contact, and there is an important difference between 'contact' and integration: the one does not inevitably or necessarily lead to the next. To add to the problem, contact taking place in the context of South African society, with its legacy of entrenched racial segregation, is likely to be experienced very differently by students who enter the institution from very different social backgrounds, and this is then further complicated by existing power-relations in each residence, where elected leaders guide new-comers as to how to behave.

No matter how committed student leaders may be to promoting integration and creating a supporting climate and culture (see Moody, 2001), the unavoidable fact is that they hold the 
'power', and in so doing they run the risk of accentuating the newcomer's feelings of inferiority, resulting in unwitting coersion to adapt or accommodate to their expectations. Of course, such encounters also hold the seeds of possibility for the construction of an oppositional identity (p20), and the strong protesting voice of the one student who dared to speak out is a case in point.

Results of this explorative account suggest that serenading is indeed a form of initiation: it includes public humiliation, minor sleep-deprivation in the form of being woken early, and embarrassing public performances involving singing and dancing. There is also a degree of coercion evident in the results of the survey. While one could argue that some level of coercion of this sort is needed at times of induction, and some discomfort is inevitable when a transition is made into a completely new environment, there is a grey area between persuasion and compulsion. Those students expressing unhappiness in the survey are significant voices - and it is clearly those voices that frequently get ignored or drowned out. There are still questions as to how free such a 'choice' actually is in a context where everyone is new, and everyone is agreeing to do something, and you might be the odd one out. Careful consideration must be given in such instances to power differences and peer pressure, and levels of embarrassment or the implied threat of ostracism for non-participation.

On the positive side, overall the survey shows significant 'improvement' as a result of compliance with the new protocol, and a largely positive experience for the overwhelming majority of first year students at the institution. One House Committee member spontaneously emailed the Dean of Students to offer her narrative: "I have seen first-hand that the new serenading policies have had such a positive influence ... giving our first years a choice when it came to serenading actually made them more excited for it ... All of our first years wanted to be involved in the process. Students who were shy were quite happy to stand in the back row and sing along ... When we made it clear that everything was voluntary it really seemed to help the first years to understand that we were not superior to them in any way and they seemed more comfortable. I would just like to thank you for the much needed and, at first, unpopular changes to the serenading tradition".

Nevertheless, the implications from this study are clear: the effects of such traditions can become insidious and invisible, deeply woven into the pattern of 'normal campus culture'. It is up to those in authority to raise awareness about such peer pressure, and send out a clear message that initiation of any sort will not be tolerated. Interventions to shift such cultures and prevent students from being unwittingly coerced into propagating them further should start early in the year, preferably during orientation, and should involve all levels.

Universities need to recognise the danger of allowing certain traditions to reproduce 'dominant discourses' which inevitably construct certain students (the ones who do not wish to participate) in deficit terms. They need to actively foster a sense of belonging and connectedness through transformation of their culture, or run the risk of not transforming dominant discourses and power relations, and excluding certain young people (cf. Badenhorst \& Kapp, 2013).

Such interventions must be ongoing, helping all students develop an understanding of power 
dynamics so they can identify initiation, regardless of context, understand the effect of hidden coercion, and recognize the potential for harm even apparently innocent activities like serenading can have. It is clear that further change management is necessary to encourage student leaders to devise new, imaginative, alternative activities in their residences to help students integrate and interact socially and to develop the kinds of young people who can lead change, resist group coercion, critically assess current practices and make ethical judgments in the face of moral dilemmas such as these.

\section{References}

Aguirre, A. (2000). Academic Storytelling: A Critical Race Theory Story of Affirmative Action. Sociological Perspectives, 43(2), 319 -39. http://dx.doi.org/10.2307/1389799

Allan, E., \& Madden, M. (2008). Hazing in View: College Students at Risk. University of Maine, College of Education and Human Development. Retrieved February 26, 2013, from http://www.hazingstudy.org/publications/hazing_in_view

Badenhorst, E., \& Kapp, R. (2013). Negotiation of Identity and Learning among First Year Medical Students. Teaching and Higher Education. Retrieved March 4, 2013, from http://www.tandfonline.com/doi/abs/10.1080/13562517.2012.753050

Bonilla-Silva, E. (2003). Racial Attitudes Or Racial Ideology? An Alternative Paradigm for Examining Actors' Racial Views. Journal of Political Ideologies, 8(1), 63-82. http://dx.doi.org/10.1080/13569310306082

Bonilla-Silva, E., \& Forman, T. (2000). I'm not a Racist, but .... : Mapping White College Students' Racial Ideology in the US. Discourse and Society, 11(1), 50-85. http://dx.doi.org/10.1177/0957926500011001003

Bonilla-Silva, E., Lewis, A., \& Embrick, D. (2004). IDidnot Get That Job because of a Black Man...: The Story Lines and Testimonies of Color-Blind Racism'. Sociological Forum, 19(4), 555-81. http://dx.doi.org/10.1007/s11206-004-0696-3

de Klerk, V., \& Radloff, S. (2009). Measuring the Effect of Diversity Interventions at a South African Residential University. International Journal of Diversity in Organisations, Communities and Nations, 10(2), 25-45.

Elliott, A., \& Judson, M. (1959). The Effect of Severity of Initiation on Liking for a Group. Journal of Abnormal and Social Psychology, 59(2), 177-181. http://dx.doi.org/10.1037/h0047195

Hammersley, M. (1995). The politics of social research. Sage Publications: Newbury, CA.

Haug, F. (1992). Beyond female masochism: memory-work and politics. London: Verso.

Hoover, N., \& Pollard, N. (1999). Initiation rites and athletics: A national surveyof NCAA sports teams. Alfred University and Reidman Insurance Co., Inc.

Hoover, N., \& Pollard, N. (2000). Initiation rites in American high schools: Anational survey. Alfred University. Retrieved March 4, 2013, from http://www.alfred.edu/hs_hazing 
Isaac, S., \& Michael, W. B. (1997). Handbook in research and evaluation: A collection of principles, methods, and strategies useful in the planning, design, and evaluation of studies in education and the behavioral sciences (3rd ed.). San Diego: Educational and Industrial Testing Services.

Jones, R. L. (2004). Black haze: violence, sacrifice, and manhood in BlackGreek-letter fraternities. Albany, NY: SUNY Press.

Kamau, C. (2012). What Does Being Initiated Severely into a Group do? The Role of Rewards. International Journal of Psychology. Retrieved March 3, 2013, from http://dx.doi.org/10.1080/00207594.2012.663957

Keating, C. F., Pomerantz, J., Pommer, S. D., Ritt, S. J. H., Miller, L. M., \& McCormick, J. (2005). Going to College and Unpacking Hazing: A Functional Approach to Decrypting Initiation Practices Among Undergraduates. Group Dynamics: Theory, Research, and Practice, 9(2), 104-126. http://dx.doi.org/10.1037/1089-2699.9.2.104

McIntyre, L. J. (1999). The practical skeptic: core concepts in sociology. Mountain View, CA: Mayfield Publishing.

Niglas, K. (2004). Tallinn Pedagogical University Dissertations on Social Sciences 8.

Nuwer, H. (1999). Wrongs of passage: fraternities, sororities, hazing and binge drinking. Bloomington, IN: Indiana University Press.

Nuwer, H. (2000). High school hazing: when rites become wrongs. New York: Grolier Publishing.

Plummer, K. (1995). Telling sexual stories. London: Routledge. http://dx.doi.org/10.4324/9780203425268

Report of the Ministerial Committee on transformation and social cohesion and elimination of discrimination in public higher institutions. (November 2008).

Salant, P., \&Dillman, D. A. (1994). How to conduct your own survey. New York: John Wiley \& Sons.

Steedman, C. (1986). Landscape for a good woman. London: Virago.

Tajfel, H., \& Turner, J. C. (1979). An Integrative Theory of Intergroup Conflict. In W. G. Austin, \& S. Worchel (Eds.), Thesocial psychology of intergroup relations (pp. 33-47). Monterey, CA: Brooks/Cole.

Vincent, L. (2008). The Limitations of 'Inter-Racial Contact': Stories From Young South Africa. Ethnic \& Racial Studies, 31(8), 1426-1451. http://dx.doi.org/10.1080/01419870701711839 
Appendix

Appendix 1. Guidelines for social activities during Orientation Week

\section{Aims}

Every year Rhodes University welcomes hundreds of new students to campus and into our residences. As part of this warm welcome, residences are encouraged to devise imaginative ways to enable these students to settle down quickly and meet new friends, who come from a variety of backgrounds. These activities should provide a pleasant and relaxing background to the more formal orientation arranged by the University, and should help in acclimatising and 'inducting' new students into their new environment. It is very important that these activities assist with orientation and are not experienced as 'initiation', which is banned at Rhodes University. (A paragraph defining initiation has been cut, for space reasons).

\section{The Requirements}

1. A session on 'orientation' and initiation must be included in the annual training of House Committees and Sub wardens, with a detailed discussion of this document, where students are made aware of their power and the potential for unwitting peer pressure to be applied.

2. As part of the first meeting with new students in each Residence, the Warden must discuss the purpose of orientation, and the difference between orientation [and initiation]. Students must be reminded that all participation in any social event in the residence is voluntary.

3. While students should be advised of safety precautions, and normal safety talks and fire alarm training should take place, fire alarms and intercom systems may not be used in order to wake students for any social activities.

4. No social activities may commence before 7 a.m.

5. House Committees and Sub wardens must be full participants in all such activities.

6. If residences wish to arrange inter-residential visits to facilitate 'meeting and greeting', then:

a. A maximum of 2 such social engagements are permitted each morning, and one such engagement each evening. Residences are encouraged to set up engagements with other residences of the same gender as well as opposite genders.

b. Students should not make undue noise when walking to and from their destinations

c. Students should be sober, and should not wear revealing clothing on such occasions (jeans / t-shirts / tracksuits are appropriate). No dress code may be compulsory.

d. House Committees must base strategies to set up conversations on a random numerical card system (i.e. not keys, shoes etc.), and must aim to encourage interaction in threesomes or larger groups (no pairings).

e. The conversations that take place should be culturally neutral and 'above-board', avoiding topics which have deliberate sexual connotations. 


\section{Macrothink}

7. If residences wish to sing as part of their social engagement:

a. the focus should be on fun and enthusiasm

b. only students who volunteer should participate

c. instrumental accompaniment may not be amplified or excessively loud

d. no lewd or lascivious gestures may accompany the songs

e. the lyrics of the songs must be approved by the House/Hall Warden.

f. Participation by any residence or student in any SRC social event (such as RU Jamming) is entirely voluntary, and any such competition should not permit lewd or foul language, or lascivious gyrations and dance moves.

8. House Committees and Sub wardens should agree on a mechanism for immediate intervention in the event of any evidence of initiation being noticed or reported. A "red card" system is a possibility. Both Warden and Hall Warden must be informed immediately of all such concerns.

Wardens will be held accountable for the clear and effective communication of these guidelines to all role-players. House Committees and Sub wardens will thereafter be held accountable for any contraventions.

\section{Copyright Disclaimer}

Copyright reserved by the author(s).

This article is an open-access article distributed under the terms and conditions of the Creative Commons Attribution license (http://creativecommons.org/licenses/by/3.0/). 